\title{
Категория лэй 美 в тексте "Ши цзина"
}

Метакультурный подход, ориентированный на исследование "редрлексивного опыта разных типов культур, их опыта самопонимания" [9], исходит из тезиса о единстве рефлексивного опыта человечества, опыта, находящего своё преломление в практиках разных культур. Руководствуясь этим подходом, мы утверждаем и единство эстетического опыта человека. При этом в центр исследования помещается экзистенциальная специфика семантики эстетических категорий, проявляющаяся в различных культурах, в нашем случае - в китайской.

Категория мәй 美 "прекрасное" принадлежит к числу важнейших категорий китайской эстетики. Прекрасное многозначно - выраженное в категории мәй, оно встречается во множестве китайских текстов, в т.ч. и в ключевых философрских текстах, таких как "Лунь юй" [14], "Мэн-цзы" [15], "Сюнь-цзы" [18] и др. в эстетическом и этическом контексте. Целью данной работы является контекстуальный анализ семантики категории лэй 美 в китайском классическом "Каноне поэзии" - "Ши цзине".

Следует прояснить этимологическое значение иероглифа лэй 美. Для этого обратимся к ряду источников: иероглифическому конкордансу "Цзя цзинь чжуан ли да цзыдянь" ("Большой словарь надписей изягувэнь, изиньвэнь, чжуаньшу и лишу") [17], классическому этимологическому словарю I в. до н.э. "Шовэнь цзецзы" [16], а также современному "Ханьцзы туцзе цзыдянь" ("Иллюстрированный этимологический словарь китайских иероглиров") [12].

Точное происхождение иероглифра мәй 美 - вопрос дискуссионный. Словари "Шовэнь цзецзы" и "Ханьцзы туцзе цзыдянь" дают нам две версии иероглифической семантики мәй 美:

- В словаре "Шовэнь цзецзы" о мэй 美говорится: "Вкусное. Состоит из [графем] ян 羊 "баран" и да 大 "большой". Баран из шести домашних животных главный для [доброй] еды. Мэй 美и шань 善 "добро" - одно значение" [16]. Происхождение иероглифра здесь связывается с приятным вкусом.

- В "Ханьцзы туцзе цзыдянь" иная версия этимологии мэй 美: "Идеограмма. Он [иероглиф] изображает человека, носящего головной убор с украшениями и означает "прекрасное". Основное значение - "прекрасное". Приводится ряд значений лэй 美, в частности: "прекрасное", "украшать", "хорошее" (xao 好)" [12, c. 1056].

- "Большой словарь надписей изягувэнь, изиньвэнь, чюуаньшу и лишу" способен внести в эту заочную полемику некоторую ясность. Он представляет собой собрание инскрипций указанных исторических стилей китайского письма. В данном издании собраны 20 вариантов написания мәй 美 [17, с. 325]. Инскрипции на гадательных костях и панцирях черепах, очевидно, отсылают нас к изображению человека в головном уборе, равно как и более поздние находки на бронзовых изделиях, шелке и бамбуковых дощечках. Это делает связь этимологии мэй 美с образом шамана, проводящим ритуалы более вероятной, как и полагает автор "Ханьцзы туцзе цзыдяня".

Этой же точки зрения в трактовке мэй 美придерживался и выдающийся исследователь китайской эстетики Ли Цзэхоу, предполагавший, что этим иероглифом в древности обозначали большого человека, носящего головной убор в форме барана, что подтверждает его власть - вероятнее всего, проводящего ритуал шамана $[11$, c. 22]. Ли Цзэхоу также подчеркивает двойствен-

КОТОВА Диана Дмитриевна, магистрант Дальневосточного федерального университета (е. Владивосток). E-mail: diana_ucheb@mail.ru 
ную роль обряда, как и человека в нем: опираясь на наскальные рисунки с изображением данного действия. Ли Цзэхоу подчеркивает, что в ритуале не только воспроизводит быт, обозначая место каждого члена в первобытного общества, но и взывает к эмоциональному опыту отдельного человека, которые он переживал во время танца или песни - неотъемлемых частей многих ритуалов и по сей день [11]. По словам В.Н. Топорова, ритуал, с точки зрения архаического сознания "связывал здесь и теперь с там и тогда и обеспечивал преемственность бытия в мире, выводимом из космологической схемы и оправдываемом связью с нею" [5, с. 15]. Через программируемую последовательность определенных действий ритуал даровал участнику ритуального действа переживание причастности к общему, и как следствие - работал на выживание общности и самого индивида.

Однако ритуал нес в себе не только этическое. Большую роль играло чувственное начало, приводя человека в "оптимальное состояние", ритуал заставлял его испытывать некую положительную эмоцию, ее можно охарактеризовать как радость, ощущение полноты бытия [5]. И это чувственное - предпосылка эстетизации ритуала, приведшая к тому, что он облекся в фрорму описывающего текста (например, поэзии, картины, сосуда), который так или иначе отсылает к чувственному восприятию ритуала.

Всё вышесказанное позволяет нам фиксировать в этимологии знака мэй 美 ритуально-эстетическое начало. Однако, как мы помним, "Шовэнь" указывает на иное, этическое значение мэй 美, синонимизируя его с понятием "доброго" шань 善или "хорошего" $x a о$ 好. $\mathrm{K}$ тому же знаки мэй 美и шань 善 объединяет общий иероглифический ключ ян 羊 "баран". Как свидетельствует "Цзя цзинь чжуан ли да цзыдянь", изначально знак шань 善включал в себя графрему ян 羊 "баран" и две графемы янь 言 "речь" [17, с. 605]. Возможно, изначально этот иероглиф запечатлел шаманский обряд или процесс дележа барана. Смысловую связь мэй 美с шань 善предполагают и два других словаря:

- "Шовэнь цзецзы": "Шань 善: Удача. Состоит из [графрем] изин 棓"спорить" и ян 羊"баран". Этот [знак] с илэй 義美 "должным и прекрасным" - одно значение" [16].

- "Ханьцзы туцзе цзыдянь": "Идеограмма. Цзиньвэнь состоит из [графрем] ян 羊 "баран" (баран выступал в качестве талисмана) и изин 誩 "спорить" (речи), [иероглиф] имел схожее значение [со словами] лэйхао 美好 "прекрасное" и "счастливое". В унифицированном варианте состоит из графем ян 羊 "баран" и янь 言 "речь". Основное значение - "счастливое", "прекрасное". Ряд иных значений шань 善: "достойный", "доброе дело", "превосходный", "дружелюбный", "хорошо знать", "владеть в совершенстве", "должно, как следует", "правильный, надлежащий" [12, с. 606].

Таким образом, предварительные итоги исследования иероглифа мэй 美 позволяют сделать следующие выводы:

- с одной стороны, этимология иероглифа лэй 美указывает на его ритуально-эстетическое происхождение. Вероятно, концепт прекрасного на уровне знака начал фоксироваться как отражение содержания какого-то первобытного ритуала. Конечно, пре-красное здесь не могло здесь нести черт эстетически возвышенного, оно было скорее пре-, чем -красное, прекрасное как необычное, отличное, т.е. отличающееся, выдающееся. Именно такое в первую очередь привлекает внимание, бросается в глаза, запоминается. В данном случае это был необычный внешний облика шамана в процессе ритуала, что и фокксирует иероглиф мэй美.

- с другой стороны, некоторая общность не только в семантике мәй 美 и шань 善 (что подчёркивается в "Шовэне"), но и отчасти в их графической структуре, указывает на возможное этическое содержание лэй美.

Этико-эстетическую двойственность в семантике мэй 美на современном материале отмечала и Тань Аошуан. Опираясь на базовый словарь современного китайского языка "Сяньдай ханьюй да цыдянь", она приводит пять значений иероглифра мэй 美:

- "красивый" (лэйли 美丽);

- "сделать красивым" (лэйжун 美容 "сделать лицо красивым" и лэйgбa 美发 "делать красивую прическу");

- "вызывающий чувство удовольствия" (например, лээицзю 美酒 "вкусное (отличное) вино" или жицзьго дэ тин мэй 日子过的挺美 "хорошо живется"); 
- "прекрасный" как "хороший" (например, в таких выражениях, как мэŭxaо dэ шиy 美好的事物 "прекрасное дело", лэйбушэн шоу 美不胜收 идиома "в глазах пестрит от красоты", чэн жэнь чжилэй 成人之美"способствовать чувству удовлетворения у людей", "делать к удовольствию других");

- диалектное значение "быть довольным собой" (например, Лаошикуалэ та иззи изюй, та изюлэй дэ ля бу дэ 老师夸了他几句, 他就没得俩不得 "Учитель его немного похвалил, а он уже на седьмом небе от счастья").

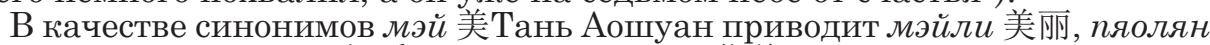
漂亮 "красивый", хаокань 好看 "хороший", юмэй 优美 "прекрасный" [3, с. 186190].

Основой для прояснения семантической связи этического и эстетического может послужить контекстуальный анализ семантики употребления категории лэй 美 в ряде ключевых текстов конфуцианской классики. Попытаемся проиллюстрировать данный тезис на примере семантического поведения мәй 美 в "Ши цзине".

"Ши цзин" 詩經 ("Книга песен", "Книга стихов", "Канон песен" или "Канон поэзии") - это поэтический сборник $[13]^{1}$, послуживший квинтэссенцией ранней китайской поэтической традиции. Выбор данного текста для анализа мэй 美 был сделан нами по нескольким причинам. Во-первых, судя по всему, данный текст содержит в себе наиболее древние слои китайской текстовой культуры. Во-вторых, бытование данного сборника текстов тесно связано с различными культурными средами, внутри которых он создавался и функционировал (ритуальная, дворцовая и др.), а именно в этих условиях начали зарождаться новые философские категории, позже закрепленные в письменных текстах учеными и каноноведами. В-третьих, входящие в него стихи-ши 詩 считались каноническими ещё во времена Конфруция. В-четвёртых, фактически восходя по своему происхождению к самым разным слоям китайского общества I тыс. до н.э., стихи "Ши цзина" фриксируют семантику слова мэй 美 в широком контексте её употребления. Как отмечает исследователь "Ши цзина" Хэ Линь: "Литературная деятельность коренится в познавательной деятельности и жизненном опыте. Поэтому интерпретация "Ши цзина" - попытка генерирования смыслов с точки зрения механизмов языка и познания" $[10$, c. 150]. Согласно когнитивной поэтике, на которую опирается ученый, именно в литературных произведениях ярче всего проявляются и отчетливее всего генерируются смыслы. Это также служит аргументом в пользу выбора обозначенных литературных памятников.

Опираясь на конфуцианскую традицию, китайцы приписывают компиляцию и редактирование "Ши цзина" Конфуцию. Как сообщали, в частности, "Исторические записки" Сыма Цяня: "В древности [стихов-ши] имелось свыше 3 тыс. текстов. Учитель Кун отбросил те из них, которые повторяли [один другой], выбрал те, [которые] имели отношение к ритуалу ли и справедливости $u^{\prime \prime}$ $[2,15.47 .18$ a]. Зафиксированное Сыма Цянем убеждение послужило поводом для возникновения точки зрения о том, что Конфуций серьезно отредактировал уже отобранный сборник, лишь убрав некоторые стихи.

По поводу создания стихов-шu 詩 М.Ю. У льянов, приводя зафиксированные в "Цзо чжуань" слова жреца-ши 師Куана [7] ${ }^{2}$, сообщает, что "шu 詩 - это песенно-поэтические произведения, которые создавались и исполнялись во время различных религиозных церемоний" [6]. И задача эта возлагалась на специальную категорию слепых жрецов-музыкантов $2 y$ 瞽, которые являлись частью общей категории жрецов $ш и$ 師). Стихи эти имели конкретную прикладную цель - они сопровождали ритуалы, объясняли, какой именно смысл в них заложен. Ли Шань в предисловии к современному изданию "Ши цзина" утверждает, что без понимания контекста ритуального действа невозможно понять и смысл сопровождающего его песни-стиха. В подтверждение своего

1 Китайские тексты, существовавшее это время, обычно применяют к "Ши цзину" термин цзунцзи总集 "сборник" или сюаньцзи 选集 "антология".

2 "Жрецы ши, создавая шу (писания), жрецы гу, создавая ши (песни), жрецы гун (со и мэн), исполняя песнопения, наставляют и увещевают [государей], дафу убеждают и вразумляют, служилые передают речения, простолюдины ропщут, торговцы перемещаются по рынкам, ремесленники подносят изделия ремёсел". 
тезиса он приводит несколько примеров. Во-первых, он подробно рассказывает о изитянь 籍田 - ритуальном вспахивании поля, исполняемое правителем, его семьей и сановниками, без знания о котором нельзя трактовать ряд стихов памятника. Во-вторых, Ли Шань освещает особенности стиха-песни "Эр цзюань". На первый взгляд, не совсем ясно, почему в первой строфе говорится о традиционно женском деле - сборе трав, а в последующих о традиционно мужском - езде верхом на лошади. Объяснение заключается в том, что во время ритуала данный стих поочередно исполняли мужчина и женщина, то становится понятно, почему в стихе два лирических героя [13].

Позже (по М.Ю. У льянову - в период Чжаньго, в рамках решения философрских задач) именно ши 詩 были включены в состав "Ши цзина" [6, с. 150151]. Предполагается и приблизительная дата появления первых вариантов будущего "Канона поэзии" - рубеж VI - V вв. до н.э. В наиболее древних текстах - например, в "Лунь юе" [14-2.2, 3.8, 3.20, 3.25, 7.14, 8.3, 8.15, 9.15, 12.10, $13.15,15.11,16.13,17.9,17.10,17.18]$ "Канон поэзии" называется просто "Ши" 詩, известно также и другое ее название - "Ши сань бай" 詩三百("Триста стихов"). Своё привычное название "Ши цзин" текст получил значительно позже своего создания - также в "Исторических заметках" Сыма Цяня (109 г. до н.э - 98 г. н.э.), где он в главе 121 "Жизнеописание конфуцианцев" ("Жу линь ле чжуань" 儒林列傳) впервые употребил слово "изин" 經, "книга" или "канон", литература, необходимая в учении $[2-121.4,121.7,121.15,121.17,121.18]$. Официально это наименование закрепилось еще позже - при династии Южная Сун (1127-1279 г.г. н.э.) - его ввел в "Пояснениях к Ши цзину" каноновед Ляо Ган (1070-1143 г.г. н.э.) [4].

В эпоху Хань будущий "Ши цзин" существовал в четырех версиях, известных как Хань ши чжуань 韩詩傳 ("Песни в ханьской передаче"), Ци ши чжуань 齊詩傳 ("Песни в циской передаче"), Лу ши чжуань 魯詩傳 ("Песни в луской передаче") и Мао ши ши чжуань 毛氏詩傳 ("Песни в передаче рода Мао") [4]. Это - версии текста, хранившиеся в региональных конфуцианских школах. Наиболее каноничным, близким к оригиналу вариантом со времен эпохи Хань, считается версия "Мао ши ши чжуань".

В нынешней редакции "Ши цзина" 305 стихов, распределенных по четырем разделам: "Го фэн" ("Нравы царств"), "Сяо я" ("Малые оды"), "Да я" ("Великие оды") и "Сун" ("Гимны"). Эти разделы соответствуют определённым жанрам древнекитайской поэзии.

Иероглифр мэй 美встречается в "Ши цзине" в 14 стихах, всего 40 раз. Частотность употребления в тексте - приблизительно 1,02 (для сравнения: частотность употребления знака в "Лунь юе" - 1,2 [14], в "Мэн-цзы" - 0,46 [15], в "Сюнь-цзы" - 0,89 [18]). Слово мәй 美в дошедшей до нас версии "Ши цзина" двадцать раз встречается в этических (либо близком к этическим) значениях "отличный", "удивительный", "выдающийся в чем-либо" [13 - I.III.13, I.VII.3, I.VII.9, I.VII.20, I.IX.2, I.XII.4] и двенадцать раз в синонимичном - "достойный", "пригодный", "лучший" [13-I.VIII.8, I.X.11, I.XII.7, I.XII.10]. Восемь раз он имеет значения эстетические - "прекрасный", "любимый" [13,-I.III.17, I.IV.4, I.V.3, I.VIII.11]. Таким образом, 80\% случаев употребления мәй 美 в "Ши цзине" - это этические (либо близкие к этическим) коннотации, и только $20 \%$ - эстетические.

Причём все случаи употребления мэй 美в "Ши цзине" относятся к стихам раздела "Го фэн". Характерно также, что мэй 美в "Ши цзине" употребляется, как правило, по отношению к людям: как к мужчинам, так и к женщинам. Из этого следует, что синонимичным словом луань 變, употребленном в одном из отрывков [13, I.II.17], обозначались неодушевленные предметы.

В стихах "Шоу жәнь" [13, I.V.3] и "И цзе" [13, I.VIII.11] мәй 美относится к описанию глаз: в "Шоу жәнь" это фрраза 美目盼兮, описывающая зрачки знатной девушки на выданье [13, I.V.3], а в "И цзе" [13, I.VIII.11] мэй 美 упоминается в фразе美目盼兮 "Прекрасные глаза сияют".

Однако всегда ли уместно трактовать мэй 美так, лишь как красивый на вид? Для этого рассмотрим некоторые из стихов подробнее.

Обратимся к стиху "Цзянь си" (в переводе А.А. Штукина - "Песнь танцора" [8, с. 46-47], в пер. В. П. Абраменко - "Огнем взор пылает" [1-с. 166]) [13, I.III.13]. В нем говорится о чувствах танцора, исполняющего ритуальный танец. Особенно нам интересна данная строфра: 


\section{云誰之思西方美人} 彼美人兮西方之人兮

Словосочетание мэй жэнь 美人 дословно переводится как "прекрасный человек". Отечетсвенными переводчиками (и А. А. Штукиным [8, с. 46-47], и В.П. Абраменко [1, с. 166]) это однозначно переведено как "красивая девушка". Т.е. думы танцора, помимо мыслей о благодати со стороны правителя, обращены и к некой девушке, что живет далеко на западе (к "Красавице с запада, что за рекой" в пер. Абраменко). Однако Ли Шань, китайский исследователь "Ши цзина", трактует данное словосочетание иначе - он говорит, что это "выдающийся, пышущий здоровьем человек" [13, с. 103]. Также ученый утверждает, что самый близкий синоним этой фрразы - шо жэнь 碩人, что дословно переводится как "выдающийся человек". Он полагает, что мәй жэнь 美 人 здесь - не некая девушка, ждущая лирического героя из дальнего странствия, а фрраза, которой танцор описывает себя сам, и соответственно - свою тоску по дому. Выдающимся он мог себя назвать потому, что до этого правитель отметил его заслуги. Следовательно, если исходить из этой трактовки словосочетания мәй жэнь 美人, то сама категория мэй 美может обнаружить семантическую близость с греческим словом $\alpha \rho \varepsilon \tau \hat{\eta}-$ последнее обычно переводится на русский язык как "добродетель" или "доблесть", также "слаженность", "пригодность" чего-либо или кого-либо. Также стоит отметить, что лирический герой стиха как бы "раскрывает" что для него значит лэй 美 - это люди с запада, его родины, что и делает их "выдающимися".

Стоит отметить, что появившийся вариант перевода мэй жэнь 美人в "Цзян си" [13, I.III.13] как "красавицы" может быть навеян тем, что похожая конструкция - с обращением мыслями к девушке - встречается в "Ши цзине" в стихе "Сан чжун" [13, I.IV.4], где юноша мысленно обращался и жаждал встречи с различными девушками (чьи конкретные женские имена обозначены в тексте).

Из контекста того или иного стиха "Ши цзина" значение мэй 美 проясняется, нам сообщается, на каком основании человеку дали эту характеристику. И если, например, в стихе "Е ю май цао" [13, I.VII.20] еще можно отнести эти расшифровки к внешней красоте человека (например, "красивое чело"), то в некоторых стихах мы видим несколько иной контекст: например, в стихе "Лу лин" [13, I.VIII.8] описывается охотник, ему дали характеристику мэй 美 не за внешнюю красоту, но, скорее, за то, что он хороший, выдающийся охотник - за то, что он правильно отдает команды гончим, правильно ведет ритуал охоты. То же можно сказать и о стихе "Фэнь цзю жу" [13, I.IX.2], в котором описывается дева Шу - характеристика мэй 美 ей дается также не за внешнюю красоту, а за её таланты в пении и речах. На наш взгляд, в данном контексте вполне уместно сказать, что мәй 美 здесь, скорее, значит "выделяющийся в каком-то деле", нежели "прекрасный". Подобное значение мәй 美, возможно, имеет место и в стихе "Фэнь цзю жу" [13, I.IX.2], где может иметься в виду не недостаток красоты внешней, но скорее недостаток навыков, достоинств, чтобы быть возницей или строителем царских колесниц, или даже больше - самому принадлежать правящей семье.

Еще одной интересной коннотацией мәй 美 является то, что оно часто появляется именно в любовной лирике [13]. Этим эпитетом довольно часто лирический герой (или лирическая героиня) характеризует свою возлюбленную (или своего возлюбленного), размышляя о нем или о ней: о его достоинствах или даже гибели на поле битвы. Это мы можем наблюдать в таких стихах, как "Цзин нюй" [13, I.III.17], "Сан чжуй" [13, I.IV.4], "Гә шэн" [13, I.X.11] и "Фан юй цюэ чао" [13, I.XII.7]. Можно предположить, что здесь речь идет не о "прекрасном внешне", но об эпитете, подразумевающем "достойный" в значении "самый лучший в моих глазах" или даже "мой возлюбленный".

Таким образом, наше исследование категории мэй 美 показало, что уже на уровне иероглифической этимологии обозначающего её знака в его графической структуре выделяются как эстетическое, так и этическое начала. Эта двойственность семантики мәй 美 хорошо видна при анализе стихов "Ши цзина". Из сорока случаев употребления лэй 美 в "Ши цзине" тридцать два раза категория употребляется в этических (или близких к этическим) значениях "отличный", "удивительный", "выдающийся в чем-либо" или "достойный", 
"пригодный", "лучший" и лишь восемь - в эстетических значениях "прекрасный", "любимый". Обнаруженное в семантике лэй 美 единство эстетического и этического характерно для раннего этапа развития текстовой культуры во многих регионах мира.

\section{Литература}

1. Абраменко В.П. Ши цзин (Канон поэзии): поэтический перевод. М.: Институт Дальнего Востока РАН, 2015. 398 с.

2. Сыма Цянь. Исторические записки (Ши цзи). В 9 т. Т. 9 / пер. с кит. и коммент. под ред. А.Р. Вяткина. М.: Вост. лит., 2010. 623 с.

3. Тань Аошуан. Китайская картина мира: Язык, культура, ментальность. М.: Языки славянской культуры, 2004. 240 с.

4. Титаренко М.Л., Аникеева С.М, Завьялова О.И Кравцова М.Е, Кобзев А.И и др. Духовная культура Китая. Том 3. Литература. Язык и письменность. М.: "Восточная литература", 2006. 727 с.

5. Топоров В.Н. О ритуале. Введение в проблематику // Архаический ритуал в фольклорных и раннелитературных памятниках. М.: Наука, 1988. 329 с. С. 7-60.

6. Ульянов М. Ю. Жрецы ши 史при дворах царств периода Чуньцю // 46-я научная конференция "Общество и государство в Китае", том XLVI, часть 2. М.: Институт востоковедения РАН, 2016 С. 127-182

7. Чунь цю Цзо чжуань ("Весны и осени" с комментарием Цзо): 1-4 гг. правления луского Инь-гуна (722-711 гг. до н.э.). М.: Гуманитарий, 2007. С. 195-214.

8. Ши цзин: Книга песен и гимнов / Пер. с кит. А. Штукина; Подгот. Текста и вступ. ст. Н. Федоренко; Комент. А. Штукина. М.: Худож. лит., 1987. 351 с.

9. Ячин С.Е., Конончук Д.В., Поповкин А.В., Буланенко М.Е. Дао и Телос в смысловом измерении культур восточного и западного типа. Владивосток: Изд-во ДВФУ, 2011. 324 c.

10. He Ling, Jimg Du. Shijing, Pingdian and Cognitive Poetics // Advances in Social Science, Education and Humanities Research, 2017. Vol. 90. P. 150-154.

11. Li Zehou. Chinese Aesthetic Tradition / University of Hawaii Press. 2010. P. 282.

12. 顾建平. 汉字图解字典. - 上海：东方, 2018. 1285 页 (Гу Цзяньпин. Иллюстрированный этимологический словарь китайских иероглифов. Шанхай: Дунфан, 2018. 1285 c.)

13. 李山. 诗经析读：全文增订插图本. - 北京：中华书局, 2018. 871 页 (Ли Шань. Анализ "Книги песен": полный текст с иллюстрациями. Пекин: Чжунхуа шуцзюй, 2018. 871 c.)

14. 论语 (Лунь юй) // Chinese Text Project, [Электронный ресурс]. URL: http:// ctext. org/analects (дата обращения 29.07.2019)

15. 孟子 (Мэн-цзы) // Chinese Text Project, [Электронный ресурс]. URL: http:// ctext. org/mengzi (дата обращения 29.07.2019)

16. 許慎. 說文解字 (Сюй Шэнь. Классический этимологический словарь). // Chinese Text Project, [Электронный pecypc]. URL: https:// ctext.org/shuo-wen-jie-zi (дата обращения: 29.07.2019)

17. 徐无闻. 甲金管隶大字典. - 成都：四川梓书, 1991. 2114 页(Сюй Увэнь. Большой словарь надписей цзягувэнь, цзиньвэнь, чжуаньшу и лишу. Чэнду: Сычуань цзышу, 1991. 2114 c).

18. 荀子 (Сюнь-цзы) // Chinese Text Project, [Электронный pecypc]. URL:http:// www.guoxue.com/book/xunzi/0008.htm (дата обращения 30.07.2019). 


\section{Транслитерация по ГОСТ 7.79-2000 система Б}

1. Abramenko V.P. Shi tszin (Kanon poehzii): poehticheskij perevod. M.: Institut Dal'nego Vostoka RAN, 2015. 398 s.

2. Syma Tsyan'. Istoricheskie zapiski (SHi tszi). V 9 t. T. 9 / per. s kit. i komment. pod red. A.R. Vyatkina. M.: Vost. lit., 2010. 623 s.

3. Tan' Aoshuan. Kitajskaya kartina mira: YAzyk, kul'tura, mental'nost'. M.: YAzyki slavyanskoj kul'tury, 2004. $240 \mathrm{~s}$.

4. Titarenko M.L., Anikeeva S.M, Zav'yalova O.I Kravtsova M.E, Kobzev A.I i dr. Dukhovnaya kul'tura Kitaya. Tom 3. Literatura. YAzyk i pis'mennost'. M.: "Vostochnaya literatura", 2006. 727 s.

5. Toporov V.N. O rituale. Vvedenie v problematiku // Arkhaicheskij ritual v fol'klornykh i ranneliteraturnykh pamyatnikakh. M.: Nauka, 1988. 329 s. S. 7-60.

6. Ul'yanov M. Yu. ZHretsy shi 史pri dvorakh tsarstv perioda CHun'tsyu // 46-ya nauchnaya konferentsiya "Obshhestvo i gosudarstvo v Kitae", tom XLVI, chast' 2. M.: Institut vostokovedeniya RAN, 2016 S. 127-182

7. CHun' tsyu Tszo chzhuan' ("Vesny i oseni" s kommentariem TSzo): 1-4 gg. pravleniya luskogo In'-guna (722-711 gg. do n.eh.). M.: Gumanitarij, 2007. C. 195-214.

8. SHi tszin: Kniga pesen i gimnov / Per. s kit. A. SHtukina; Podgot. Teksta i vstup. st. N. Fedorenko; Koment. A. SHtukina. M.: KHudozh. lit., 1987. 351 s.

9. YAchin S.E., Kononchuk D.V., Popovkin A.V., Bulanenko M.E. Dao i Telos v smyslovom izmerenii kul'tur vostochnogo i zapadnogo tipa. Vladivostok: Izd-vo DVFU, 2011. $324 \mathrm{~s}$.

10. He Ling, Jimg Du. Shijing, Pingdian and Cognitive Poetics // Advances in Social Science, Education and Humanities Research, 2017. Vol. 90. P. 150-154.

11. Li Zehou. Chinese Aesthetic Tradition / University of Hawaii Press. 2010. P. 282.

12. 顾建平. 汉字图解字典. -上海: 东方, 2018. 1285 页 (Gu TSzyan'pin. Illyustrirovannyj ehtimologicheskij slovar' kitajskikh ieroglifov. SHankhaj: Dunfan, 2018. 1285 s.)

13. 李山. 诗经析读: 全文增订插图本. - 北京: 中华书局, 2018. 871 页 (Li SHan'. Analiz "Knigi pesen": polnyj tekst s illyustratsiyami. Pekin: Chzhunkhua shutszyuj, 2018. $871 \mathrm{~s}$.)

14. 论语 (Lun' yuj) // Chinese Text Project, [Ehlektronnyj resurs]. URL: http:// ctext. org/analects (data obrashheniya 29.07.2019)

15. 孟子 (Mehn-tszy) // Chinese Text Project, [Ehlektronnyj resurs]. URL: http:// ctext.org/mengzi (data obrashheniya 29.07.2019)

16. 許慎.說文解字 (Syuj SHehn'. Klassicheskij ehtimologicheskij slovar'). // Chinese Text Project, [Ehlektronnyj resurs]. URL: https:// ctext.org/shuo-wen-jie-zi (data obrashheniya: 29.07.2019)

17. 徐无闻. 甲金篆隶大字典. - 成都: 四川梓书, 1991. 2114 页(Syuj Uvehn'. Bol'shoj slovar' nadpisej tszyaguvehn', tszin'vehn', chzhuan'shu i lishu. Chehndu: Sychuan' tszyshu, 1991. 2114 s).

18. 荀子 (Syun'-tszy) // Chinese Text Project, [Ehlektronnyj resurs]. URL:http:// www. guoxue.com/book/xunzi/0008.htm (data obrashheniya 30.07.2019). 


\section{Котова Д. Д. Категория мэй 美 в тексте "Ши цзина"'".}

В статье в рамках метакультурного подхода был произведен этимологический анализкитайскойэстетическойкатегориилэй 美"прекрасное", атакжеконтекстуальный анализ употребления иероглифа мэй 美 в классическом конфуцианском памятнике "Ши цзин" ("Канон Поэзии"). Отмечена смысловая связь мэй 美 с этической категории шань 善 "доброе". Приводится интерпретация ряда стихов "Ши цзина", содержащих слово мэй 美. Выделяются два базовых кластера значений мәй 美 - этический и эстетический, при этом обнаружено, что этические коннотации мәй 美встречаются в "Ши цзине" значительно чаще. Это позволяет наметить путь, по которому развивалось дальнейшее осмысление прекрасного в китайской эстетической парадигме.

Ключевые слова: китайская фбилософбия, конфуциинство, "Ши изин", эстетика, прекрасное, иероглифическая этимология

Kotova D. D. Category mei 美 in the text of "Book of Poetry'"'.

In the article, within the framework of the metacultural approach, an etymological analysis of the Chinese aesthetic category mei 美 "beauty" was carried out, as well as a contextual analysis of the use of the mei 美character in the classical Confucian monument "Book of Poetry" ("Shi Jing"). The semantic connection of mei 美 with the ethical category of shan 善 "good" is noted. The interpretation of a number of "Shi Jing" verses containing the word $m e i$ 美 is given. There are two basic clusters of meanings of mei 美 - ethical and aesthetic, while it was found that the ethical connotations of mei 美 are found much more often in the "Book of Poetry". This allows us to outline the path along which further understanding of the beautiful in the Chinese aesthetic paradigm developed.

Key words: Chinese philosophy, Confucianism, "Book of Poetry", Aesthetics, Beauty, Etymology of Chinese Characters

Для цитирования: Котова Д. Д. Категория мэй 美 в тексте "Ши цзина"'" // Ойкумена. Регионоведческие исследования. 2021. № 2. С. 140-147. DOI: 10.24866/1998-6785/2021-2/140147

For citation: Kotova D. D. Category mei 美 in the text of "Book of Poetry"'" // Ojkumena. Regional researches. 2021. № 2. P. 140-147. DOI: 10.24866/1998-6785/2021-2/140-147 